\title{
Scientist quits climate-change panel
}

WASHINGTON DC

A prominent climate-change scientist has resigned from a US government panel, saying that colleagues tried to suppress his views.

Roger Pielke, of Colorado State University in Fort Collins, stepped down from the US Climate Change Science Program (CCSP) on 13 August. He says he quit in part because other panel members were trying to rewrite a report chapter he was charged with overseeing. "I was being

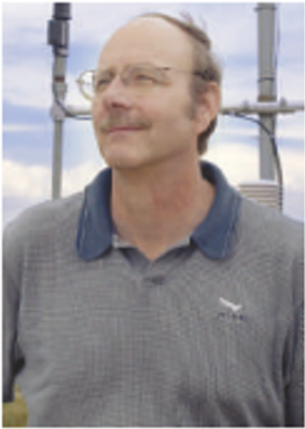

Roger Pielke claims his views were editedout. findings, but says that they narrow the remit of the report too much. "The CCSP charge was much broader than these three papers," he contends. The chapter was edited to bolster this narrowed view, he says.

Thomas Karl, who oversees the 22-member panel, admits that Pielke's chapter was edited. But he plays down the changes: "The new version was based on what had already been done - the changes were just an effort to push the process forward. prevented from including my views, he says.

Pielke is well known for his stance that other factors as well as carbon dioxide emissions cause climate change. The report is on temperature trends in the lower atmosphere, the first of 21 overviews commissioned by the CCSP. The group was set up by President George W. Bush to provide comprehensive reports on climate-change science for policy-makers.

Last month, some of the panel published papers in Science previewing parts of the report (see Nature 436, 896; 2005). The three papers suggest that observational problems are to blame for inconsistent measurements of atmospheric warming.

Pielke doesn't disagree with the published
Pielke's departure is "unfortunate", says outgoing CCSP director James Mahoney, but his views will still be partly expressed in the final version. Pielke plans to submit detailed points during a public-comment period after the report is released later this autumn.

The resignation could have adverse effects, says John Holdren, an environmental-policy expert at Harvard University. ${ }^{\circ}$ On a politically controversial issue like climate change, each little hiccough makes people wonder whether everything is in doubt, ${ }^{,}$Holdren warns. ${ }^{\alpha}$ That perception can only be offset by a chorus of scientific voices saying that the findings are robust."

Geoff Brumfiel

\section{$\mathrm{NIH}$ ethics rules come off probation}

\section{WASHINGTON DC}

Six months after interim ethics guidelines shook up the US National Institutes of Health (NIH), permanent rules have been announced.

The regulations came into effect on 30 August. They ban NIH researchers from consulting for biotechnology or pharmaceutical companies, but work with trade or professional societies is allowed.

$\mathrm{NIH}$ chief Elias Zerhouni said last week that he would evaluate the ban on consulting in a year's time. In 2003, the Los Angeles Times unmasked researchers who accepted large consulting fees from companies whose products were being studied.

Under the new rules, no one at the $\mathrm{NIH}$ is allowed to hold shares directly related to their research. But most of them can now own unrelated shares in the biotechnology and pharmaceutical fields. Senior staff "anyone with final decision-making authority or next-to-final decision-making authority ${ }^{n}$, according to Zerhouni - will have to limit holdings in each company to $\$ 15,000$, and to a total of $\$ 50,000$ for healthcare funds.

Ezekiel Emanuel, the chair of an advocacy group for NIH researchers, is cautiously pleased with the new rules. "I think they are certainly much more sensible than before," he says. But his group has no plans to disband: Emanuel says that manyother policies still sap morale at the agency.

This week, Derek LeRoith resigned his job as chief of diabetes research at the NIH's National Institute of Diabetes and Digestive and Kidney Diseases, in part because of poor morale and because of the onerous interim ethics rules. "The rules are tough," he says. "They haven't loosened them as much as I thought they would."

Emma Marris 